\title{
Role of age of incidence, parity, body mass index and socioeconomic class in endometrial carcinoma
}

\author{
Neha A. Nimbark* \\ Department of Obstetrics and Gynecology, Parul Institute of Medical Sciences and Research, Vadodra, Gujarat, India \\ Received: 11 December 2019 \\ Accepted: 04 January 2020

\section{*Correspondence:} \\ Dr. Neha A. Nimbark, \\ E-mail: nehanimbark@gmail.com \\ Copyright: (C) the author(s), publisher and licensee Medip Academy. This is an open-access article distributed under \\ the terms of the Creative Commons Attribution Non-Commercial License, which permits unrestricted non-commercial \\ use, distribution, and reproduction in any medium, provided the original work is properly cited.
}

\begin{abstract}
Background: Endometrial carcinoma is the most common gynecologial malignancy in world. The main aim is to study epidemiological factors of Ca body uterus in our hospital. The present study was designed to evaluate the age of incidence of carcinoma body uterus and study role of parity, body mass index and socioeconomic class in carcinoma body.

Methods: This is a prospective study of 50 cases of endometrial carcinoma who were treated in a single unit of the hospital from April 2010 to March 2012 (2 years) conducted at the department of gynaecological oncology G. C. R. I., Ahmedabad. Observational study was done. All these data were combined and tabulated in frequency table simple percentage analysis is used for frequency and percentage analysis is applied to create a contingency table from the frequency distribution and represent the collected data for better understanding. Descriptive statistics were obtained for all variable.

Results: Maximum number of patients were in age group of 50-59 years. Mean age was 58 years. Maximum patients were multiparous (54\%). 4 patients were nulligravida (9\%). $70 \%$ were overweight and obese. Majority of patients $(72 \%)$ belong to middle and higher socio-economic class.

Conclusions: It was noted that the incidence for ca endometrium is related to age, parity, BMI and socioeconomic class at our centre.
\end{abstract}

Keywords: Age, Body mass index, Carcinoma endometrium, Demographical factors, Parity, Socioecomic class

\section{INTRODUCTION}

Uterine cancer, cancer of the uterus (womb), or endometrial cancer is the: Fourth most common cancer in women. Most common gynecologic malignancy and accounts for $6 \%$ of all cancers in women. In India, it is third most common gynecologic malignancy. In India, the total number of estimated new cases of endometrial cancer in 2018 is 13, 328 with an estimated 5010 deaths. The age standardized incidence rate (ASIR) of endometrial cancer in India is 2.1/100,000 women. ${ }^{1}$ The median age for diagnosis of uterine cancer is 61 with the largest number of patients between 50 to 59 years. However, the number of younger women with uterine cancer is going up. Increase incident of endometrial carcinoma due to,

- Increased clinical awareness

- Improved technique for early detection like hysteroscopy

- Increased life expectancy

- Increased use of exogenous estrogen.

\section{Changes in histopathological criteria for diagnosis}

It is predominantly a disease of affluent, obese, postmenopausal women of low parity. Classically it affects affluent, obese, nulliparous, infertile, hypertensive 
and diabetic, white women. However, it can occur in absence of all this factors. Early diagnosis is key. Most uterine cancers develop over a period of years. They may start as less serious problems such as endometrial hyperplasia, which is an overgrowth of cells in the lining of the uterus. Fortunately, many uterine cancers are found early because of warning signs such as abnormal or postmenopausal bleeding. If uterine cancer is found in the earliest stages, it often can be treated successfully.

\section{METHODS}

This is a cohort study of 50 cases of endometrial carcinoma who were treated in a single unit of the hospital from April 2010 to March 2012 (2 years) conducted at the department of gynecological oncology G.C.R.I., Ahmedabad.

All selected cases had histological proven disease. Fractional curettage and endocervical curettage were performed in each patient. If the curettage was performed outside, then slides were reviewed at our pathology department.

\section{Inclusion criteria}

- All patients with histological proven disease.

\section{Exclusion criteria}

- Outside operated patients without complete documentation or previous reports and patients who came for follow up less than 3 months.

Study of each case was carried out noting the following details. Name, age, residence, registration number, date of admission and a discharge, occupation, socioeconomic class, chief complaint, origin, duration and progress of disease in detail. Past history and family history was also asked. Detailed menstrual history and obstetric history was also noted. General examination especially for weight height, anaemia and systemic examination of each system was carried out. Body mass index (BMI) was measured and calculated as the ratio of maternal weight and height $\left(\mathrm{kg} / \mathrm{m}^{2}\right)$ at diagnosis. According to the WHO classification of BMI for Asian/Indian women, the BMIs for underweight, normal weight, overweight and obese are under $18.4 \mathrm{~kg} / \mathrm{m}^{2}, 18.5$ $22.99 \mathrm{~kg} / \mathrm{m}^{2}, 23-27.49 \mathrm{~kg} / \mathrm{m}^{2}$ and over $27.50 \mathrm{~kg} / \mathrm{m}^{2}$, respectively.

Observational study was done. All these data were combined and tabulated in frequency table. Observations from these were then compared with other studies. Sociodemographic factors were investigated as independent variables. Age, BMI, parity are quantitative variables whereas Socio economical class is qualitative variable. Descriptive statistical analysis were applied. Cross tabulation of this categorical data is be done with through Microsoft Excel. Simple percentage analysis is used for frequency and percentage analysis is applied to create a contingency table from the frequency distribution and represent the collected data for better understanding.

\section{Statistical analysis}

Descriptive statistics were obtained for all variables. Continuous variables which were normally distributed were expressed using mean and standard deviation, and non-normal continuous variables were expressed using median and range. For categorical variables, percentages were used. This was done manually.

\section{RESULTS}

The study population consisted of 50 patients diagnosed with primary carcinoma body uterus. Results of all demographical factors were studied separately.

Age range of patients with endometrial carcinomas.

Table 1: Age of incidence.

\begin{tabular}{|lll|}
\hline Age in years & No. of cases (present series) & $\%$ \\
\hline$<40$ & 3 & $6 \%$ \\
\hline $40-49$ & 8 & $16 \%$ \\
\hline $50-59$ & 19 & $38 \%$ \\
\hline $60-69$ & 14 & $28 \%$ \\
\hline $70-79$ & 6 & $12 \%$ \\
\hline
\end{tabular}

Maximum numbers of patients are in age group of 50-59 years. The median age for the diagnosis is 58 years in this series. More than half the patients are premenopausal, and young women and girls may be affected in endometrial stromal sarcomas. In present study one patient aged 15 years had endometrial stromal sarcoma (Table 1).

Table 2: Socio-economic class.

\begin{tabular}{|lll|}
\hline Class & No. of cases (present series) & $\%$ \\
\hline Lower & 14 & $28 \%$ \\
\hline Middle & 26 & $52 \%$ \\
\hline Higher & 10 & $20 \%$ \\
\hline
\end{tabular}

Frequency of patients according to socio economical class.

Table 3: Parity.

\begin{tabular}{|lll|}
\hline Parity & No. of cases (present series) & $\%$ \\
\hline Nulligravida & 04 & $8 \%$ \\
\hline $1-2$ & 19 & $38 \%$ \\
\hline $3-4$ & 21 & $42 \%$ \\
\hline$>5$ & 06 & $12 \%$ \\
\hline
\end{tabular}

In our study the socioecomic status of patients were tabulated. Table shows that about patients belong 52\% 
patients belong to middle and $20 \%$ patients belong to higher socio-economic class (Table 2).

Total number of deliveries of each patient. Highest percentage for $3^{\text {rd }}$ and $4^{\text {th }}$ para. $42 \%$ of our patients were para 3 or para 4 (Table 3 ).

One out of 50 was unmarried, 4 were nullipara. Most of them are multiparous.

Table 4: Body mass index.

\begin{tabular}{|lll|}
\hline BMI & No. of cases (present series) & $\%$ \\
\hline$<23$ & 10 & $20 \%$ \\
\hline $23-25$ & 5 & $10 \%$ \\
\hline $25-32.5$ & 25 & $50 \%$ \\
\hline$>32.5$ & 10 & $20 \%$ \\
\hline
\end{tabular}

Body mass index of all patients are classified according to Indian standards. Maximum patients in our study are overweight and obese. Total of $70 \%$ were of BMI more than or equal to 25 (Table 4).

Results show that body mass index is higher in patients of ca endometrium. In our series percentage of patients with BMI more than 25 up to 32.5 is $50 \%$. Whereas lower and higher $\mathrm{BMI}$ is $20 \%$.

\section{DISCUSSION}

Endometrial carcinoma is mainly disease of fifth or sixth decade of life. The majority of women diagnosed with endometrial cancer are peri- or postmenopausal between the ages of 50 and 65.2 The average age at diagnosis is 61.3. However, the risk of developing endometrial cancer increases with advancing age. For example, a woman under the age of 40 has a 1 in 1423 risk of developing the disease, but a woman older than 70 has a 1 in 81 risk. $^{4}$ further if we compare age of incidence with different studies it is also comparable.

\section{Table 5: Comparison of frequency of endometrial carcinoma in this study with previously reported studies.}

\begin{tabular}{|llll|}
\hline $\begin{array}{l}\text { Age in } \\
\text { years }\end{array}$ & H. Krissi & $\begin{array}{l}\text { Koichi } \\
\text { Fukuda }\end{array}$ & $\begin{array}{l}\text { Present } \\
\text { series (2012) }\end{array}$ \\
\hline$<50$ & $11.04 \%$ & $23.2 \%$ & $22 \%$ \\
\hline$>50$ & $79.55 \%$ & $76.8 \%$ & $78 \%$ \\
\hline
\end{tabular}

Present study is compared with the study of H. Krissi and Koichi Fulcuda. ${ }^{5}$ In all studies majority of patients are > 50 years of age (approx. 80\%). Our study is comparable to those (Table 5). Endometrial carcinoma is mainly disease of fifth or sixth decade of life. In most reports, women with UPSC and clear cell cancers are reported to be older (median age 65 to 70 ) than those with endometrioid cancers. According to Perez-Medina T, the mean age of patients with non-endometrioid carcinomas was significantly higher than the age in the group with Endometrioid carcinomas. ${ }^{6}$

For a few types of cancer, lower socioeconomic status is associated with higher incidence, and for even more cancer types it is associated with having a less favorable tumor stage at diagnosis. For endometrial cancer, however, there is no clear evidence of such associations with socioeconomic status. There is a need for analysis of sociodemographic disparities in EC incidences according to stage at diagnosis, which may provide support for trying to improve early detection of EC. ${ }^{7}$ As compared to cervical carcinoma which is a disease of lower class; endometrial carcinoma is disease of higher class. According to Indian council of medical research in India the relative risk of high socioeconomic status is $1.3 .^{1}$

The median parity of G.ELA's study was only two. ${ }^{8}$ Though endometrial carcinoma is a disease of low parity, in present series most of the patients are multiparous. This is because in India most of the women are multiparous. This is similar to certain Indian studies showing higher incidence as number of pregnancies increases. In a study conducted at Tata memorial hospital showed higher numbers in multiparous women. ${ }^{9}$

Friedenreich et al found that women with a BMI of 30-40 $\mathrm{kg} / \mathrm{m}^{2}$ had 1.78 times (95\% CI 1.41-2.26) increased risk of endometrial cancer compared to those of normal BMI. ${ }^{10}$ Cancers attributable to overweight and obesity in several studies. In 2010 Parkin DM found that relative risks of 1.52 in Overweight and 2.31 in Obese. ${ }^{11}$ It has been estimated that $38.4 \%$ of endometrial cancer cases in 2012 were associated with diabetes and BMI. ${ }^{12}$ The analysis of cohort and case studies also confirms the positive correlation between overweight and obesity and the risk of developing endometrial cancer among both Asians and non-Asians. ${ }^{13}$ The results of another study also showed that the correlation between endometrial cancer and BMI was $0.51(\mathrm{p}<0.05) .{ }^{14}$

\section{Funding: No funding sources Conflict of interest: None declared Ethical approval: Not required}

\section{REFERENCES}

1. Indian Council of Medical Research: consensus document for the management of uterine cancer, $2018 . \quad$ Available at: https://www.icmr.nic.in/sites/default/files/whats_new /Draft_Document_of_Uterine_Cancer.docx.

2. Purdie DM, Green AC. Epidemiology of endometrial cancer. Best Pract Res Clin Obstet Gynaecol. 2001;15(3):341-54.

3. Howlader N, Noone AM, Krapcho M, Neyman N, Aminou R, Waldron W, et al. SEER Cancer Statistics Review, 1975-2008. National Cancer Institute. 
4. Siegel R. Cancer statistics. The impact of eliminating socioeconomic and racial disparities on premature cancer deaths. A Cancer J Clin. 2011;61(4):212-36.

5. Hachisuga T, Fukuda $\mathrm{K}$, Hirakawa $\mathrm{T}$, Kawarabayashi T. The effect of nulliparity on survival in endometrial cancer at different ages. Gynecol Oncol. 2001;82(1):122-6.

6. Perez-Medina T, Engels V, Salazar F, Bueno B, Sanfrutos L, de la Fuente J. Anatomopathologic subtypes of endometrial carcinoma: case-control study of 122 cases. Epidemiol Ultrasound Clin Med Oncol. 2007;1:CMO-S367.

7. Madison T, Schottenfeld D, James SA, Schwartz AG, Gruber SB. Endometrial cancer: socioeconomic status and racial/ethnic differences in stage at diagnosis, treatment, and survival. Am J Public Health. 2004;94(12):2104-11.

8. Elia G, Garfinkel DA, Goldberg GL, Davidson S, Runowicz CD. Surgical management of patients with endometrial cancer and cervical involvement. Eur J Gynaecol Oncol. 1995;16(3):169-73.

9. Balasubramaniam G, Sushama S, Rasika B, Mahantshetty U. Hospital-based study of endometrial cancer survival in Mumbai, India. Asian Pacific J Cancer Prevent. 2013;14(2):977-80.

10. Friedenreich C, Cust A, Lahmann PH, Steindorf K. Anthropometric factors and risk of endometrial cancer: the European prospective investigation into cancer and nutrition. Cancer Causes Control. 2007;18(4):399-413.

11. Parkin DM, Boyd L. Cancers attributable to overweight and obesity in the UK in 2010. Br J Cancer. 2011;105 Suppl 2(Suppl 2):S34-S37.

12. Pearson-Stuttard J, Zhou B, Kontis V, Bentham J, Gunter MJ, Ezzati M. Worldwide burden of cancer attributable to diabetes and high body-mass index: a comparative risk assessment. Lancet Diabet Endocrinol. 2018;6:e6-e15.

13. Zhang Y, Liu H, Yang S, Zhang J, Qian L, Chen X. Overweight, obesity and endometrial cancer risk: results from a systematic review and meta-analysis. Int J Biol Markers. 2014;29:21-9.

14. Khazaei Z, Hasanpour Dehkordi A, Amiri M, Adineh HA. The incidence and mortality of endometrial cancer and its association with body mass index and human development index in Asian population. WCRJ. 2018;5(4):e1174.

Cite this article as: Nimbark NA. Role of age of incidence, parity, body mass index and socioeconomic class in endometrial carcinoma. Int $\mathbf{J}$ Reprod Contracept Obstet Gynecol 2020;9:762-5. 